\title{
С.Л. ПАРФЕНОВА,
}

к.э.н., первый заместитель директора РИЭПП, заведующая отделом проблем научнотехнологической политики и развития науки, г. Москва, Россия, parfyonova.s.|@yandex.ru

\section{В.Н. ДОЛГОВА,}

к.э.н., доцент, заведующая сектором социально-экономических проблем развития научно-технологической сферы РИЭПП, г. Москва, Россия, vlada8@bk.ru

\section{B.B. БОГАТОВ,} научный сотрудник РИЭПП, г. Москва, Россия, d-benz.92@mail.ru

\section{Н.В. ХАЛТАКШИНОВА,} лаборант-исследователь РИЭПП, г. Москва, Россия, nadya01.95@gmail.com

\section{В.Я. КОРОБАТОВ,}

лаборант-исследователь РИЭПП, г. Москва, Россия, vkorobatov@mail.ru

\section{МЕТОДИЧЕСКИЙ ПОДХОД \\ К ФОРМИРОВАНИЮ РУБРИКАТОРОВ- \\ ПЕРЕХОДНИКОВ ДЛЯ АНАЛИЗА \\ НАПРАВЛЕНИЙ WЕВ OF SCIENCE \\ И SCOPUS В PAЗPEЗЕ ПРИOРИТЕТОВ \\ СТРАТЕГИИ НАУЧНО-ТЕХНОЛОГИЧЕСКОГО РАЗВИТИЯ РФ1}

УДК 001,004

Парфенова С.Л., Долгова В.Н., Богатов В.В., Халтакшинова А.В., Коробатов В.Я. Методический подход $\kappa$ формированию рубрикаторов-переходников для анализа направлений Web of Science и Scopus в разрезе приоритетов Стратегии научно-технологического развития РФ (Российский научноисследовательский институт экономики, политики и права в научно-технической сфере, ул. Земляной вал, 50A, строение 6, г. Москва, Россия, 105064)

Аннотация. В статье описывается методический подход к разработке рубрикаторов-переходников Web of Science и Scopus в системе приоритетов Стратегии научно-технологического развития Российской Федерации. Актуальность данной задачи обусловлена необходимостью проведения статистических и динамических ретроспективных, проспективных и двунаправленных исследований. В статье дано описание иерархических структур рубрикаторов Web of Science и Scopus и их классификационных кодов. Выявлены сложности соотнесения рубрикаторов между собой и в системе приоритетов СНТР. Определены принципы формирования рубрикаторов-переходников в разрезе приоритетов СНТР. Представлен алгоритм формирования рубрикаторов-переходников Web of Science и Scopus в системе приоритетов СНТР Представлен алгоритм распределения числа научных статей по научным категориям в системе приоритетов СНТР методом группировки. Проведен сравнительный анализ научных категорий Российской Федерации и в мире по числу научных статей, индексируемых в Web of Science и Scopus, в системе приоритетов СНТР.

Ключевые слова: методический подход, рубрикатор-переходник, приоритеты научно-технологического развития, коды Web of Science, коды Scopus, метод группировки, статистический анализ.

DOI 10.22394/2410-132X-2017-4-2-143-153

Цитирование публикации: Парфенова С.Л., Долгова В.Н., Богатов В.В., Халтакшинова А.В., Коробатов В.Я. (2018)

Методический подход к формированию рубрикаторов-переходников для анализа направлений Web of Science и Scopus в разрезе приоритетов Стратегии научно-технологического развития РФ // Экономика науки. Т. 4. № 2. С. 143-153.

(C) С.Л. Парфенова,

В.Н. Долгова, В.В. Богатов,

Н.В. Халтакшинова,

В.Я. Коробатов, 2018 г.
1 Исследование выполнено в рамках государственного задания Министерства образования и науки Российской Федерации «Мониторинг и анализ публикационной и патентной активности российской и мировой науки в целях обеспечения реализации государственной научно-технической политики» (проект № 28.12616.2018/12.1). 
K

ачество международных сопоставлений различных индикаторов, определяющих степень развития сферы науки и технологий в разрезе приоритетов Стратегии научно-технологического развития Российской Федерации [1] (далее - приоритеты (НТР), в том числе определяется логистическими принципами, заложенными в основу согласования информационных потоков, содержащих сведения о научных (научно-технических) результатах в базах данных Web of Science и Scopus. Установить взаимосвязь между этими потоками возможно на основе переходников между рубрикаторами баз данных Web of Science и Scopus, структурирующих эти потоки в системе приоритетов СНТР.

В основу рубрикаторов Web of Science и Scopus (далее - международных рубрикаторов) положена иерархическая классификация научных направлений. Существуют различные подходы к процессу классификации [2-5]. Все они предполагают, как минимум, три процедуры:

- процедуру построения классификатора;

- процедуру описания классификатора;

- процедуру использования классификатора.

В теории классификации можно выделить 2 направления [6]:

- классификация по объектам рассмотрения (например, классификация химических элементов - таблица Д.И. Менделеева), универсальная десятичная классификация публикаций (УДК) и др.;

- классификация по типовым задачам диагностики (отрасли промышленности, группы однородной продукции).

В научно-исследовательской работе была поставлена задача по соотнесению объектов рассмотрения (кодов международных рубрикаторов) к задачам диагностики (приоритетам СНTP) на этапе «генерация знаний».

Существующие международные рубрикаторы разработаны с целью тематической систематизации данных; способствуют формированию навигационных систем, позволяющих проводить анализ большого объема информации и осуществлять визуализацию его результатов в форме инфографики на основе современных методов и способов библиометрии, информетрии и наукометрии.

Международные рубрикаторы облегчают доступ к сведениям о научной (научно-технической) информации и сформированы на принципах:

- построения 2-х или 3-х уровневой иерархической структуры;

- постоянно развивающейся системы навигации.

Как уже отмечено, иерархические структуры рубрикаторов Web of Science и Scopus делятся в зависимости от выбранного классификационного признака на уровни. Каждый уровень в соответствии со своим классификационным признаком делится на подуровни. Для отражения классификационных взаимосвязей между уровнями применяются классификационные коды, которые способствуют логической обработке информации. В иерархических системах международных рубрикаторов для упорядочения объектов применяется система последовательного кодирования.

Рубрикатор Web of Science [7] состоит из трех уровней. Первый уровень имеет цифровой код от «l» до «б» и включает шесть областей науки рубрикатора ОЕСD [8]. Второй уровень рубрикатора имеет трехзначный цифровой код, формулу которого можно представить символами «***». Первый символ означает код первого уровня рубрикатора, вторые два - код подуровня. Например, код «1.02» означает область науки - «естественные и точные науки», подуровень - «компьютерные и информационные науки». Всего 39 подуровней, что отличает рубрикатор второго уровня Web of Science от рубрикатора второго уровня OECD, который включает 42 отрасли науки (более детализированы код «2»и код «4» первого уровня). Самый детализированный - третий подуровень рубрикатора Web of Science, он содержит 253 категории. Код, характеризующий третий квалификационный подуровень, имеет буквенное обозначение из двух символов. Таким образом, общая формула кода выглядит следующим образом «***XX».

Рубрикатор Scopus [9] содержит в себе два уровня. В системе Scopus он имеет название ASJC (All Science Journals Classification). 
Систематизация кодов по областям науки в рубрикаторе Scopus отсутствует. Первый уровень включает 26 основных категорий, которые объединяют в себе 322 направления второго уровня. Кодировка рубрикатора цифровая из четырех символов (формула кода «****»). Первые две цифры относятся к одной из 27 основных категорий, а последние две цифры относятся к подкатегории в основной категории. Чтобы избежать «лидирующих» нулей, нумерация начинается с 10** («мультидисциплинарные науки»), а затем $11^{* *}$ («сельскохозяйственные и биологические науки») до $36^{* *}$ («медицинские профессии»). Вторые две цифры относятся к кодировке второго уровня.

В процессе работы по соотнесению рубрикаторов возникли определенного рода сложности, среди которых можно выделить следующие:

- сбор и накопление данных осуществляют независимые друг от друга организации, территориально расположенные в разных странах мира и самостоятельно определяющие принципы систематизации и анализа данных, а также права доступа к ним;

- сложности установления смысловых текстовых связей между рубрикаторами, сформированными по разным основаниям;

- отсутствие способов идентификации научных (научно-технических) результатов, полученных в рамках междисциплинарных научных исследований, кроме отнесения их к категории «междисциплинарные научные исследования» или разнесение их по разным кодам рубрикаторов;

- «парадигмальные сдвиги в науке» [10], вследствие которых содержание существующих рубрикаторов оказывается неадекватно новым реалиям науки и должно быть пересмотрено.

Приоритеты научно-технологического развития Российской Федерации сформулированы в Стратегии научно-технологического развития Российской Федерации и в общем виде представляют собой систему первого уровня.

Рубрикаторы-переходники научных публикаций в разрезе приоритетов СНТР предложено проводить на основе методического подхода, который состоит в сравнении предметно-содержательных (семантических) аспектов текстовых элементов приоритетов СНТР с аналогичными аспектами текстовых элементов рубрикаторов Web of Science и Scopus.

Методический подход основан на следующих принципах формирования рубрикаторов-переходников в разрезе приоритетов CHTP [11]:

- общее основание текстовой связанности рубрикаторов-переходников с международными рубрикаторами и приоритетами СНТР;

- первичность связующей функции (смыслового акцента) при определении текстовых связей между приоритетами СНTP и международными рубрикаторами;

- 100\% охват кодов изучаемой совокупности (кодов рубрикаторов Web of Science и Scopus);

- уровневая соотносимость (первый уровень рубрикатора-переходника соотносим с третьим уровнем рубрикатора Web of Science и вторым уровнем рубрикатора Scopus);

- кодовое дедублирование (неповторяемость в рубрикаторе-переходнике кодов рубрикаторов Web of Science и Scopus).

Рубрикатор-переходник представляет собой таблицу перекодировки из одной навигационной системы в другую.

В процессе составления рубрикаторов-переходников авторы статьи столкнулись со следующими сложностями:

- приоритеты СНТР означают векторы научно-технологического развития Российской Федерации, основанные на целых блоках научных направлений, не связанных между собой;

- без понимания смысловых аспектов, заложенных в тот или иной приоритет СНТР, невозможно устанавливать текстовые связи между приоритетами СНTP и категориями рубрикаторов Web of Science и Scopus;

- рубрикаторы-переходники требуют тематического экспертного обсуждения.

Алгоритм формирования рубрикаторов-переходников Web of Science и Scopus в системе приоритетов СНTP состоял из следующих этапов:

Выявление ключевых текстовых элементов приоритетов СНТР (табл. 7, выделены курсивом), сопоставимых по смыслу и семантически с текстовыми элементами международных рубрикаторов. 


\section{Ключевые текстовые элементы приоритетов СНTP}

\begin{tabular}{|c|c|}
\hline $\begin{array}{c}\text { Приори- } \\
\text { тет }\end{array}$ & Ключевые текстовые элементы приоритетов СНТР \\
\hline A & $\begin{array}{l}\text { цифровые, роботизированные системы, способы конструирования и системы обработки } \\
\text { больших объемов данных, машинного обучения и искусственного интеллекта } \\
\text { интеллектуальные производственные технологии } \\
\text { новые материалы }\end{array}$ \\
\hline Б & $\begin{array}{l}\text { экологически чистая и ресурсосберегающая энергетика } \\
\text { добыча и глубокая переработка углеводородного сырья } \\
\text { источники, способы транспортировки и хранения энергии }\end{array}$ \\
\hline B & $\begin{array}{l}\text { медицина, здравоохранение и технологии здоровьесбережения } \\
\text { лекарственные препараты }\end{array}$ \\
\hline$\Gamma$ & $\begin{array}{l}\text { агро- и аквахозяйство } \\
\text { средства химической и биологической защиты сельскохозяйственных растений и животных } \\
\text { хранение и переработка сельскохозяйственной продукции, продукты питания }\end{array}$ \\
\hline Д & $\begin{array}{l}\text { противодействие техногенным, биогенным, социокультурным угрозам, терроризму } \\
\text { и идеологическому экстремизму, а также киберугрозам и иным источникам опасности } \\
\text { для общества, экономики и государства }\end{array}$ \\
\hline$F$ & $\begin{array}{l}\text { интеллектуальные транспортные и телекоммуникационные системы на территории Российской } \\
\text { Федерации }\end{array}$ \\
\hline & $\begin{array}{l}\text { международные транспортные системы, международные транспортно-логистические системы, } \\
\text { космическое и воздушное пространства, океан }\end{array}$ \\
\hline Ж & $\begin{array}{l}\text { взаимодействие человека и природы, человека и технологий, социальных институтов } \\
\text { методы гуманитарных и социальных наук }\end{array}$ \\
\hline
\end{tabular}

Определение текстовых связей политематических классификаторов Web of Science (третий уровень), Scopus (второй уровень) с ключевыми текстовыми элементами приоритетов СНТР по характеру связующих функций, а именно смысловые (понятийно-смысловые) связующие функции и структурные связующие функции.

Формирование перечня кодов третьего уровня рубрикатора Web of Science в системе приоритетов СНТP (табл. 2, на примере приоритета А).

Формирование перечня кодов второго уровня рубрикатора Scopus в системе приоритетов СНТР (табл. 2, на примере приоритета А).

Экспертное согласование перечней кодов международных рубрикаторов в разрезе приоритетов СНTP.

В итоге работы сформированы рубрикаторы-переходники Web of Science и Scopus в системе приоритетов СНTP (табл. 2, на примере приоритета А).
Рубрикаторы-переходники предназначены для проведения одномоментных и динамических исследований структуры и числа публикаций, индексируемых в Web of Science и Scopus, в разрезе приоритетов CHTP.

На основе рубрикаторов-переходников методом группировки [12] проведен анализ числа научных статей, индексируемых в базах данных Web of Science и Scopus, в системе приоритетов СНТР по Российской Федерации и миру. Группировка проводилась по совокупному числу научных статей за период 2013-2017 гг. Алгоритм группировки включал следующие этапы:

1. Определение числа групп по формуле Герберта Стерджесса (1):

$$
n=1+3.322 * \lg N
$$

где:

$n$ - число групп разбиения по каждому приоритету СНTP;

$N$ - число научных категорий по каждому приоритету CHTP по данным Web of Science и по данным Scopus. 


\section{Коды международных рубрикаторов по приоритету А}

Таблица 2

\begin{tabular}{|c|c|}
\hline & Коды классификатора Web of Sc \\
\hline & 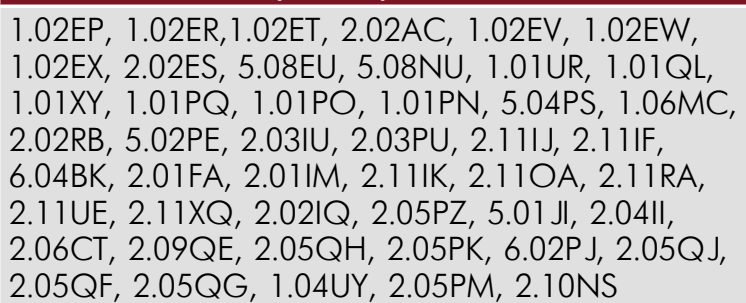 \\
\hline
\end{tabular}

2. Удаление «выбросов» (максимальные и минимальные значения показателя, которые выбиваются из нормального распределения).

3. Определение величины интервала для каждого приоритета по данным Web of Science и по данным Scopus по Российской Федерации и миру, формула (2):

$$
i=\frac{X_{\max }-X_{\min }}{n}
$$

где:

$X_{\text {max }}$ и $X_{\text {min }}$ - максимальное и минимальное значения суммарного числа публикаций по научным категориям в рамках каждого приоритета СНTP.

4. Проведение вторичной группировки, основанной на укрупнении интервалов, т.е. выделении более характерных групп и избавлении от более мелких, неинформативных групп.

По итогам первичной группировки по данным Web of Science и Scopus (дата обращения 30.03.2018 г.) определено число научных категорий и групп в системе приоритетов СНТР (табл. 3). Число научных категорий и групп одинаково по российским и общемировым статьям.

\begin{tabular}{|} 
Коды классификатора Scopus \\
1702, 1700, 1802, 1404, 1711, 1701, 1712, 1706, \\
$2614,1703,1704,1707,2611,3315,1710,1705$, \\
3309, 2610, 3109, 2609, 1804, 2613, 2602, 2608, \\
2603, 2600, 2601, 2612, 2605, 2604, 2607, 2214, \\
3110, 1903, 1709, 1803, 1800, 1801, 2606, 2207, \\
2200, 2210, 2206, 2201, 2215, 2216, 1708, 2205, \\
2209, 3105, 2212, 1607, 2208, 3307, 2500, 2211, \\
2502, 2503, 2506, 2504, 2505, 2508, 2507, 2501
\end{tabular}

На основе результатов первичной группировки выявлена характерная закономерность, заложенная в основу вторичной группировки, а именно: в большинстве приоритетов наблюдаются три типичные группы [13].

Первая группа (малозначительная) состоит из большого числа научных категорий с наименьшим (или нулевым) числом научных статей - аутсайдеры. Третья группа (приоритетная) включает небольшое число научных категорий с наибольшим числом научных статей - лидеры. Вторая группа (доминантная, расположенная между двумя крайними группами) содержит небольшое число научных категорий со средним числом научных статей. Результаты вторичной группировки совокупного числа публикаций (за период 20132017 гг.), индексируемых в базе данных Web of Science и Scopus, в системе приоритетов СНТР в Российской Федерации и мире представлены на рис. 1.

Как видно на рис. 1, большинство приоритетов СНТР разбиваются на три группы, лишь приоритет Д и Е состоит из двух групп

Таблица 3

\section{Число категорий и групп (2013-2017 гr.)}

\begin{tabular}{|c|c|c|c|c|} 
Приоритет & $\begin{array}{c}\text { Число научных } \\
\text { категорий по данным } \\
\text { Web of Science (N) }\end{array}$ & $\begin{array}{c}\text { Число групп } \\
\text { по данным Web } \\
\text { of Science (n) }\end{array}$ & $\begin{array}{c}\text { Число научных } \\
\text { категорий по данным } \\
\text { Scopus (N) }\end{array}$ & $\begin{array}{c}\text { Число групп } \\
\text { по данным } \\
\text { Scopus (n) }\end{array}$ \\
\hline A & 47 & 7 & 64 & 7 \\
\hline Б & 29 & 6 & 38 & 6 \\
\hline В & 71 & 7 & 136 & 8 \\
\hline Г & 20 & 5 & 18 & 6 \\
\hline Д & 23 & 5 & 32 & 4 \\
\hline E & 13 & 4 & 11 & 6 \\
\hline Ж & 49 & 7 & 33 & 6 \\
\hline
\end{tabular}




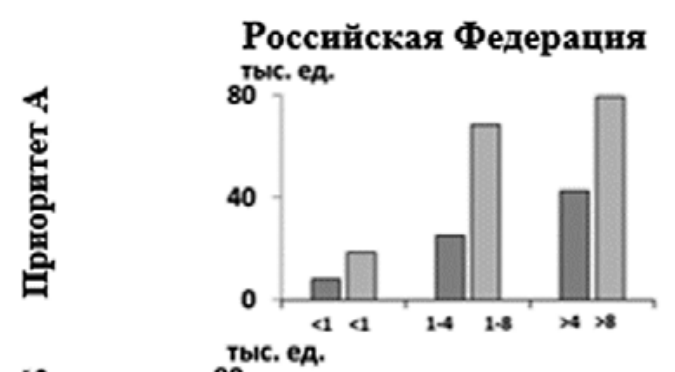

品 тыс. eA.

Росснйская Федерацня Thic. eA.

$$
90
$$

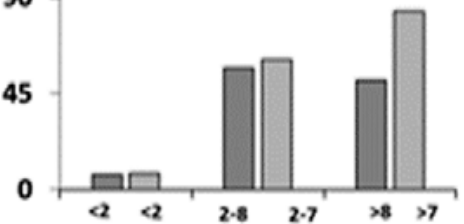

THC. eA.

禺

占

点

蛅

旨 тыс. ед.

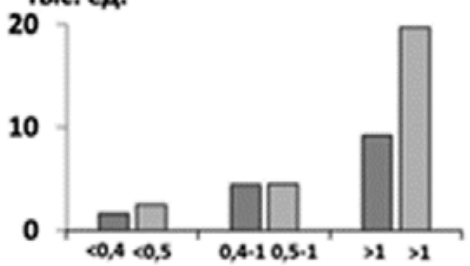

$\square$ Web of Science

$$
20
$$

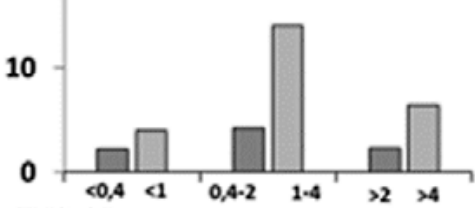
тыс. ед.

20

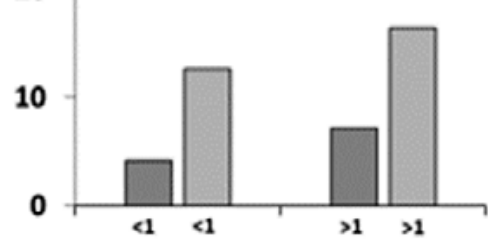
rыc. eA.

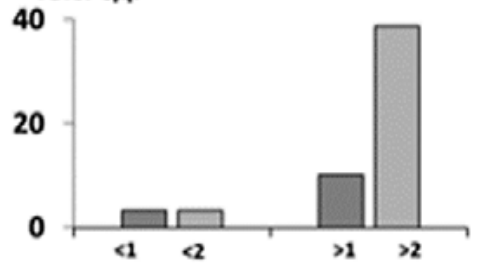

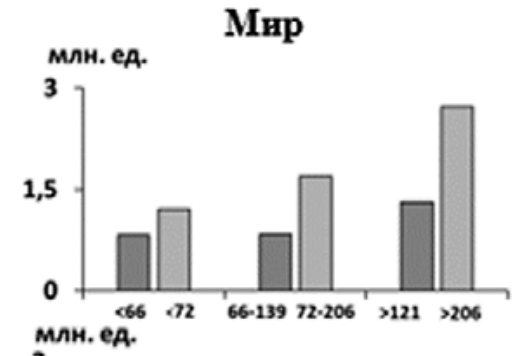

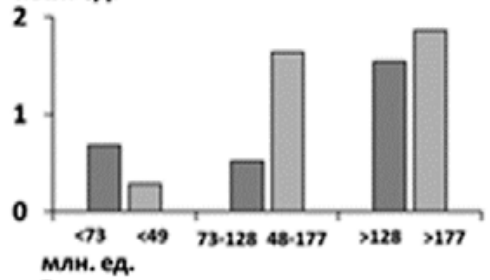
мин.ед.

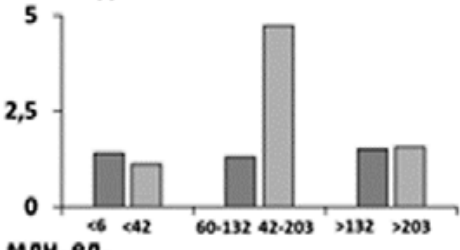
млн. еА. тыс. eA.

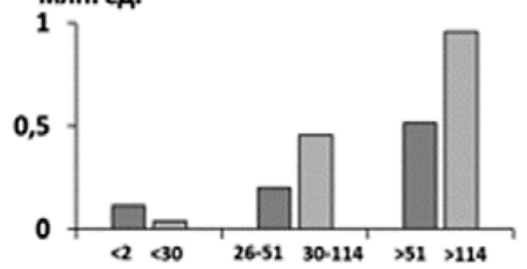
млн. ед.

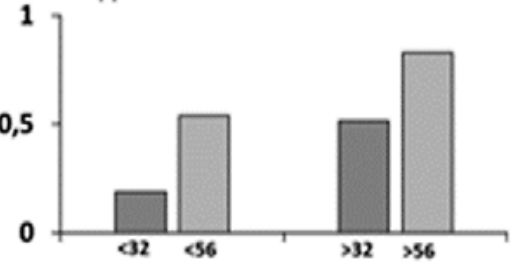
млн.ед.
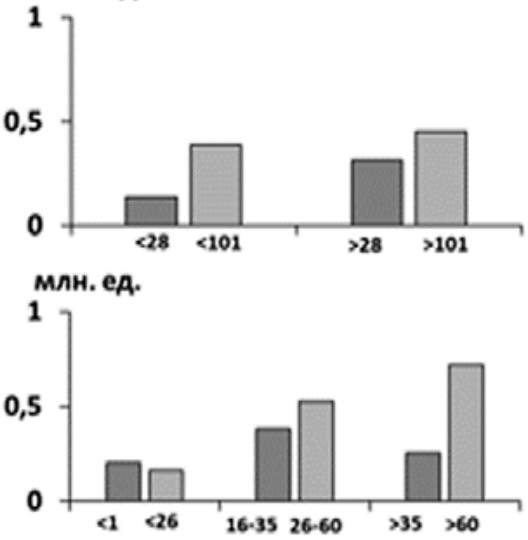

$\square$ Scopus

Рис. 1. Группировка совокупного числа научных статей (2013-2017 гr.) в системе приоритетов СНTP по России и миру 
в связи С небольшим числом включенных в них научных категорий (приоритет Д - 23 научные категории, приоритет E - 13 научных категорий).

На основе вторичной группировки проанализирован состав научных категорий приоритетной группы (лидеры), в которую вошли научные категории с наибольшим числом научных статей (табл. 4-10). Цветом выделены научные категории, по которым отмечена высокая публикационная активность (группа лидеров) российских исследователей и в мире.

По приоритетам А и Б (табл. 4, табл. 5), наибольшее число российских научных статей представлено по категориям, которые вызывают интерес в мире, к ним относится математика, машиностроение, химические технологии, материаловедение, физика, химическая инженерия и др.

\section{Научные категории по приоритету А}

Таблица 4

\section{Научные категории Web of Science}

PФ Математика-общая

Прикладная математика

Механика

Инструменты и приборы

Металлургия

и металловедение

Химические технологии и промышленность

Материаловедение-

междисциплинарное мир

Электротехника и электроника

Наноматериалы и нанотехнологии
Научные категории Scopus

$P \Phi$ мир

Общая математика Компьютерная и прикладная наука

Прикладная математика

Электротехника

Электронные оптические и магнитные материалы

Общее машиностроение Машиностроение

Химия материалов

Общее материаловедение

\section{Научные категории по приоритету Б}

\begin{tabular}{|c|c|c|c|}
\hline \multicolumn{2}{|c|}{ Научные категории Web of Science } & \multicolumn{2}{|c|}{ Научные категории Scopus } \\
\hline РФ & мир & PФ & мир \\
\hline \multicolumn{2}{|c|}{ Физика конденсированного состояния } & \multicolumn{2}{|c|}{ Физика конденсированного состояния } \\
\hline \multicolumn{2}{|c|}{ Прикладная физика } & $\begin{array}{c}\text { Ядерная физика и физика } \\
\text { высоких энергий }\end{array}$ & - \\
\hline $\begin{array}{c}\text { Физика- } \\
\text { междисциплинарная }\end{array}$ & Оптика & Атомная и молекуля & ая физика, оптика \\
\hline \multicolumn{2}{|c|}{ Химия-междисциплинарная } & \multicolumn{2}{|c|}{ Общая химия } \\
\hline- & $\begin{array}{c}\text { Науки об окружающей } \\
\text { среде }\end{array}$ & \multicolumn{2}{|c|}{ Общая химическая инженерия } \\
\hline \multicolumn{2}{|c|}{ Физическая химия } & \multicolumn{2}{|c|}{ Физическая и теоретическая химия } \\
\hline- & Энергетика и топливо & - & Органическая химия \\
\hline
\end{tabular}




\section{Научные категории по приоритету В}

\begin{tabular}{|c|c|c|c|}
\hline \multicolumn{2}{|c|}{ Научные категории Web of Science } & \multicolumn{2}{|c|}{ Научные категории Scopus } \\
\hline РФ & мир & РФ & мир \\
\hline \multicolumn{2}{|c|}{ Биохимия и молекулярная биология } & - & Биохимия \\
\hline Микробиология & $\begin{array}{c}\text { Биотехнология и приклад- } \\
\text { ная микробиология }\end{array}$ & - & Молекулярная биология \\
\hline Клиническая биохимия & $\begin{array}{c}\text { Общественное } \\
\text { здравоохранение, } \\
\text { гигиена окружающей } \\
\text { среды, гигиена труда }\end{array}$ & - & $\begin{array}{c}\text { Общая биохимия, } \\
\text { генетика и молекулярная } \\
\text { биология }\end{array}$ \\
\hline $\begin{array}{c}\text { Генетика } \\
\text { и наследственность }\end{array}$ & Онкология & Урология & - \\
\hline- & Нейробиология & - & - \\
\hline- & Хирургия & - & - \\
\hline- & Цитология & Цитология & - \\
\hline \multirow[t]{2}{*}{ - } & \multirow[t]{2}{*}{$\begin{array}{l}\text { Фармакология } \\
\text { и фармацевтика }\end{array}$} & $\begin{array}{l}\text { Фармакология, } \\
\text { токсикология } \\
\text { и фармацевтика } \\
\text { (общие вопросы) }\end{array}$ & - \\
\hline & & Фармацевтическая наука & - \\
\hline $\begin{array}{c}\text { Экспериментальная } \\
\text { медицина }\end{array}$ & Терапия и лечебное дело & - & Общая медицина \\
\hline
\end{tabular}

\section{Научные категории по приоритету Г}

\section{Научные категории Web of Science}

$P \Phi$

$-$

\begin{tabular}{c}
- \\
- \\
- \\
\hline-
\end{tabular}

\section{Биология моря и пресных вод}

Продукты питания и технологии производства (сельскохозяйственные науки)

Ветеринария Зоология

Науки о растениях

$$
\text { Пищевые науки }
$$$$
\text { и технологии }
$$

(прочие технологии)

\section{Научные категории Scopus}

$P \Phi$

мир

Экология, эволюция, динамика изменения и таксономия

\section{Сельскохозяйственные и биологические науки \\ Агрономия и земледелие}

Науки о животных и зоология

Науки о растениях

Науки о пище
По приоритетам В и Г (табл. 6, табл. 7) публикационные тренды российских иссле- дователей практически не совпадают с мировыми трендами. 
Научные категории по приоритету Д

Таблица 8

\begin{tabular}{|c|c|c|c|}
\hline \multicolumn{2}{|c|}{ Научные категории Web of Science } & \multicolumn{2}{|c|}{ Научные категории Scopus } \\
\hline РФ & мир & $P Ф$ & мир \\
\hline \multicolumn{2}{|c|}{ Экология } & \multicolumn{2}{|c|}{ Экология } \\
\hline - & & - & $\begin{array}{c}\text { Здоровье, токсикология } \\
\text { и мутагенез }\end{array}$ \\
\hline \multicolumn{2}{|c|}{ Метеорология и науки об атмосфере } & \multicolumn{2}{|c|}{ Общие экологические науки } \\
\hline - & Менеджмент & $\begin{array}{c}\text { Общий бизнес, } \\
\text { менеджмент } \\
\text { и бухгалтерский учет }\end{array}$ & $\begin{array}{c}\text { Бизнес и международное } \\
\text { управление }\end{array}$ \\
\hline - & $\begin{array}{c}\text { Предпринимательская } \\
\text { деятельность }\end{array}$ & $\begin{array}{c}\text { Общая экономика, } \\
\text { эконометрика и финансы }\end{array}$ & Стратегия и управление \\
\hline \multicolumn{2}{|c|}{ Экономика } & \multicolumn{2}{|c|}{ Экономика и эконометрика } \\
\hline \multicolumn{2}{|c|}{ Электрохимия } & - & Электрохимия \\
\hline & Политические науки & - & $\begin{array}{c}\text { Управление, мониторинг, } \\
\text { политика и право }\end{array}$ \\
\hline- & Юриспруденция & - & Юриспруденция \\
\hline- & - & \multicolumn{2}{|c|}{ Сейсмология } \\
\hline
\end{tabular}

Научные категории по приоритету Е

Таблица 9

\begin{tabular}{|c|c|c|c|}
\hline \multicolumn{2}{|c|}{ Научные категории Web of Science } & \multicolumn{2}{|c|}{ Научные категории Scopus } \\
\hline PФ & мир & $P \Phi$ & мир \\
\hline \multicolumn{2}{|c|}{ Астрономия и астрофизика } & \multicolumn{2}{|c|}{ Астрономия и астрофизика } \\
\hline & & $\begin{array}{l}\text { Общая физика } \\
\text { и астрономия }\end{array}$ & - \\
\hline & & $\begin{array}{c}\text { Физика и астрономия } \\
\text { (общие вопросы) }\end{array}$ & - \\
\hline & & Космология & - \\
\hline \multicolumn{2}{|c|}{ Телекоммуникации } & \multicolumn{2}{|c|}{ Аэрокосмическая техника } \\
\hline \multicolumn{2}{|c|}{ Океанография } & \multirow{2}{*}{ Океанография } & \multirow{2}{*}{ - } \\
\hline - & Водные ресурсы & & \\
\hline - & Физическая география & - & $\begin{array}{c}\text { География, } \\
\text { планирование и развитие }\end{array}$ \\
\hline
\end{tabular}

По приоритетам Д, Е, Ж (табл. 8-10) публикационные тренды российских исследователей совпадают с мировыми трендами по отдельным категориям, среди них - экология, история, культурология, философия, психология.

Использование рубрикаторов-переходников Web of Science и Scopus в системе приоритетов СНТР даст возможность проводить как статистические, так и динамические исследования [14] в ретроспективе и перспективе,

что позволит проследить изменение структуры и динамики числа научных публикаций за период от 5 до 10 лет, а также проводить международные сопоставления. Дальнейшие исследования направлены на совмещение публикационных и патентных потоков в системе приоритетов СНТР, что в свою очередь потребует разработку классификатора-переходника на основе международного патентного классификатора. 


\section{Научные категории по приоритету Ж}

Научные категории Web of Science PФ

\author{
мир \\ Образование \\ и педагогика
}

Психология-междисциплинарная

Палеонтология

Междисциплинарные исследования в области гуманитарных наук

Социология
Общественные наукимеждисциплинарные
Научные категории Scopus

PФ

мир

Образование

\begin{tabular}{|c|c|}
\hline \multicolumn{2}{|c|}{ Образование } \\
\hline- & Психология развития \\
\hline $\begin{array}{c}\text { Природные } \\
\text { и ландшафтные } \\
\text { заповедники }\end{array}$ & $\begin{array}{l}\text { Языковедение } \\
\text { и лингвистика }\end{array}$ \\
\hline $\begin{array}{c}\text { Здравоохранение } \\
\text { (как социальная наука) }\end{array}$ & Лингвистика и язык \\
\hline Общие социальные науки & $\begin{array}{c}\text { Социология } \\
\text { и политология }\end{array}$ \\
\hline Гендерные исследования & - \\
\hline $\begin{array}{c}\text { История и философия } \\
\text { науки }\end{array}$ & История \\
\hline Антиковедение & $\begin{array}{c}\text { Искусство } \\
\text { и гуманитарные науки }\end{array}$ \\
\hline \multicolumn{2}{|c|}{ Культурология } \\
\hline Философия & - \\
\hline
\end{tabular}

Философия

Философия

\section{ЛИТЕРАТУРА}

1. Указ Президента Российской Федерации от 1 декабря 2016 г. № 642 (2016) Стратегия научно-технологического развития Российской Федерации / Официальный сайт Президента России. http://www.kremlin.ru/acts/bank/41449.

2. Философский энциклопедический словарь (1983) / Гл. ред. Л.Ф. Ильичев, П.Н. Федосеев, С.М. Ковалев, В.Г. Панов. М.: Советская энциклопедия. $840 \mathrm{c}$.

3. Шрейдер Ю.А. (1973) Логика классификации // Научно-техническая информация. Серия 1. № 51. С. 3-7.

4. Понкин И.В. (2017) Классификация как метод научного исследования, в частности в юридической науке // Вестник Пермского университета. Юридические науки. Вып. 37. С. 249-259.

5. Розова С.С. (1986) Классификационная проблема в современной науке. Новосибирск: Наука. $224 \mathrm{c}$.

6. Орлов А.И. (2014) Математические методы теории классификации // Научный журнал КубГАУ. № 01(095). C. 423-459.

7. Web of Science (2018) Web of Knowledge. http://apps.webofknowledge.com.
8. Working Party of National Experts on Science and Technology Indicators (2012) OECD, 27.02.2012. https://www.oecd.org/science/inno/38235147. pdf.

9. Scopus (2018) Scopus. https://www.scopus.com.

10. Соколова Н.Ю. (2016) Новые возможности отечественных универсальных классификаций (на примере ББК) // Библиосфера. № 4. С. 112-115.

11. Турбина О.А., Савельева О.А. (2006) Принцип классификации текстовых связей // Вестник Южно-Уральского государственного университета. № 6. Серия: Лингвистика. Вып. 3. С. 53-59.

12. Долгова В.Н., Медведева Т.Ю. (2017) Статистика: учебник и практикум для бакалавров - 2-е изд., перераб. и доп. / М.: Издательство Юрайт. $627 \mathrm{c}$.

13. Этапы статистического исследования: первичная обработка результатов статистического наблюдения (2005) / ГУ ВШЭ. https://www.hse.ru/ data/415/588/1239/lect2ec2005.pdf.

14. Холматова К.К., Харькова О.А., Гржибовский А.М. (2016) Классификация научных исследований в здравоохранении // Экология человека. № 1. С. 57-64. 


\section{REFERENCES}

1. Order of The President of the Russian Federation dated 1 December 2016 № 642 (2016) Strategy of scientific and technological development of the Russian Federation / Official website of the Russian President. http://www.kremlin.ru/acts/ bank/41449.

2. Philosophical Encyclopaedic Dictionary (1983) / Ch. Ed. L.F. Ilyichev, P.N. Fedoseev, S.M. Kovalev, V.G. Panov. Moscow: Soviet Encyclopedia. 840 p.

3. Shreider Yu.A. (1973) Classification logic // Scientific and technical information. Series 1. № 51. P. 3-7.

4. Ponkin I.V. (2017) Classification as a method of scientific research, in particular in legal science // Bulletin of Perm University. Juridical sciences. Issue 37. P. 249-259.

5. Rozova S.S. (1986) Classification problem in modern science. Novosibirsk: Science. 224 p.

6. Orlov A.I. (2014) Mathematical Methods of Classification Theory // Scientific Journal of KubSU. № 01 (095). P. 423-459.

7. Web of Science (2018) Web of Knowledge. http://apps.webofknowledge.com.
8. Working Party of National Experts on Science and Technology Indicators (2012) OECD, 27.02.2012. https://www.oecd.org/science/inno/38235147.pdf.

9. Scopus (2018) Scopus. https://www.scopus.com.

10. Sokolova N.Yu. (2016) New possibilities of domestic universal classifications (on the example of the BBK) // Bibliosphere. № 4. P. 112-115.

11. Turbina O.A., Savelieva O.A. (2006) Principle of classification of textual links // Bulletin of South Ural State University. № 6. Series: Linguistics. Issue. 3. P. 53-59.

12. Dolgova V.N., Medvedeva T.Yu. (2017) Statistics: textbook and practical work for bachelors -2 nd ed., Pererab. and additional. / Moscow: Publishing House Yurayt. 627 p.

13. Stages of statistical research: primary processing of statistical observation results (2005) / HSE. https://www.hse.ru/data/415/588/1239/ lect2ec2005.pdf.

14. Kholmova K.K., Kharkov O.A., Grzybovsky A.M. (2016) Classification of scientific research in public health // Human ecology. № 1. P. 57-64.

UDC 001, 004

I Parfenova S.L., Dolgova V.N., Bogatov V.V., Khaltakshinova A.V., Korobatov V.Y. Methodical approach to the

I formation of rubricators-adapter for analysis of Web of Science and Scopus area in terms of priorities The

I strategy of scientific and technological development of The Russian Federation (Russian Research Institute of

I Economics, Policy and Law in the Scientific and Technical Sphere, ul. Earth Shaft, 50A, Building 6, Moscow, Russia,

I 105064)

I Abstract. The article describes a methodical approach to the development of Web of Science and Scopus

1 rubricators-adapter in the system of priorities of the Strategy of scientific and technological development of the

I Russian Federation. The relevance of this problem is due to the need for statistical and dynamic retrospective,

I prospective and bidirectional studies. The article presents the description of the hierarchical Web of Science and

- Scopus categories structures and their classification codes. Revealed the difficulty of categories correlating among

I themselves and in the system of priorities SSTD. The principles of categories-adapters formation in the priorities

I SSTD context. Article is presented the algorithm of rubricators-adapters Web of Science and Scopus formation

I in the system of SSTD priorities. The algorithm of number scientific articles distribution on scientific categories in

I system of SNTR priorities by grouping method is presented. A comparative analysis of Russian Federation scientific

I categories and the world in the number of scientific articles indexed in the Web of Science or Scopus, in the system

of SSTD priorities.

I Key words: methodical approach, rubricator-adapter, priorities of scientific and technological development, Web of Science codes, Scopus codes, method of grouping, statistical analysis. 